\title{
The mosquitoes of Armenia: review of knowledge and results of a field survey with first report of Aedes albopictus
}

\author{
Lusine Paronyan ${ }^{1}$, Lilit Babayan ${ }^{1}$, Arsen Manucharyan ${ }^{1}$, Dezdemonia Manukyan ${ }^{1}$, Haykuhi $\operatorname{Vardanyan}^{1}$, \\ Gayane Melik-Andrasyan ${ }^{1}$, Francis Schaffner ${ }^{2,3}$, and Vincent Robert ${ }^{4, *}$ \\ ${ }^{1}$ National Center of Disease Control and Prevention, Ministry of Health, 25 Heratsi str., Yerevan 0025, Republic of Armenia \\ ${ }^{2}$ Francis Schaffner Consultancy, Lörracherstrasse 50, 4125 Riehen, Switzerland \\ ${ }^{3}$ National Centre for Vector Entomology, Institute of Parasitology, Vetsuisse Faculty, University of Zurich, \\ Winterthurerstrasse 266a, 8057 Zürich, Switzerland \\ ${ }^{4}$ MIVEGEC Unit, IRD, CNRS, University of Montpellier, 911, avenue Agropolis, BP 64501, 34394 Montpellier cedex 5, France
}

Received 12 December 2019, Accepted 23 May 2020, Published online 8 June 2020

\begin{abstract}
Background: In 2016, a field study was implemented in all Armenian provinces in order to update knowledge on the presence and distribution of both native and invasive mosquito species. Larvae and adult mosquitoes were sampled and identified on the basis of their morphology. Supplementary field surveys were performed in 2017-2018. Results: Between June 20 and July 12, 2016, 117 localities were visited. A total number of 197 sampling units were checked, of which 143 (73\%) were positive for mosquitoes (with 1-6 species per sampling unit). A total number of 4157 mosquito specimens were identified to species or species complex level. Ten species represent first records for Armenia: Aedes albopictus, Ae. annulipes, Ae. cataphylla, Ae. cinereus/geminus (probably Ae. cinereus), Ae. flavescens, Anopheles plumbeus, Coquillettidia richiardii, Culex martinii, Cx. torrentium and Culiseta subochrea. The invasive species Ae. albopictus was recorded in a single locality (Bagratashen) at the border point with Georgia, along the main road Tbilisi-Yerevan. This species was further recorded in 2017 and 2018, demonstrating its establishment and spread in north Armenia. These surveys confirm the presence of vectors of malaria parasites (in particular An. sacharovi) and West Nile virus (Cx. pipiens). Conclusion: The knowledge of the Armenian mosquito fauna is extended to a list of 28 species. The record of Aedes albopictus, an important potential vector of many arboviruses, has important implications for public health.
\end{abstract}

Key words: Biodiversity, Culicidae, Invasive species, Vector, Malaria, Arbovirus.

Résumé - Les moustiques d'Arménie : synthèse des connaissances et résultats d'une étude de terrain avec une première mention pour Aedes albopictus. Contexte : En 2016, nous avons réalisé une étude sur le terrain dans toutes les provinces du pays dans le but d'actualiser la présence et la distribution des espèces de moustiques aussi bien natives qu'invasives. Les moustiques récoltés aux stades larvaires et adultes ont été identifiés sur des critères morphologiques. Des suivis additionnels ont été réalisés en 2017 et 2018. Résultats : Entre le 20 juin et le 12 juillet 2016, 117 localités ont été visitées. Au total, 197 unités de collecte ont été prospectées dont 143 (73\%) se sont révélées positives pour les moustiques (avec de 1 à 6 espèces par unité de collecte). Au total, 4157 spécimens ont été identifiés au niveau de l'espèce ou du complexe d'espèces. Dix espèces ont été observées pour la première fois en Arménie : Aedes albopictus, Ae. annulipes, Ae. cataphylla, Ae. cinereus/geminus (probablement Ae. cinereus), Ae. flavescens, Anopheles plumbeus, Coquillettidia richiardii, Culex martinii, Cx. torrentium et Culiseta subochrea. L'espèce invasive Ae. albopictus a été observée dans une seule localité (Bagratashen) à la frontière avec la Géorgie, sur l'axe routier principal Tbilisi-Yerevan. Cette espèce a également été observée en 2017 et en 2018, faisant la preuve de son installation et de sa diffusion dans le nord de l'Arménie. Ces suivis confirment la présence des vecteurs de Plasmodium humains (en particulier An. sacharovi) et du virus West Nile (Cx. pipiens). Conclusion : La connaissance de la faune culicidienne d'Arménie progresse, avec une liste actualisée à 28 espèces. L'observation d'Aedes albopictus, un important vecteur potentiel de nombreux arbovirus, a d'importantes implications en termes de santé publique.

\footnotetext{
*Corresponding author: vincent. robert@ird. fr
} 


\section{Introduction}

The Republic of Armenia is a landlocked country in the Caucasus region of Eurasia. The territory is mostly mountainous with fast flowing rivers and few forests. The climate is highland continental, i.e. hot summers and cold winters. The country is characterised by a large variety of natural environments. Several distinct landscape zones are described: deserts, semi-deserts, dry steppes, steppes, woodlands, sub-alpine, and alpine lands. The conditions of these various natural landscape zones from the lowland plains to high mountains rely primarily on altitude, and shape the diversity of both flora and fauna, including insects. The country is divided into 11 provinces, of which 10 are regions (marzes) - Aragatsotn, Ararat, Armavir, Gegharkunik, Kotayk, Lori, Shirak, Syunik, Tavush, and Vayots Dzor - and the last one is Yerevan, the capital city.

The only mosquito-borne disease historically registered in Armenia is malaria. This disease was known to be highly endemic in the country from ancient times. It had persisted in Armenia throughout the centuries but was absent for 31 years, during the period of 1963-1993 [6, 24, 25, 28]. From 1994 to 2005, 4013 (1722 autochthonous) Plasmodium vivax malaria cases were registered $[4,7,13]$ with the highest number in 1998 (1156) of which 542 were autochthonous; 31.3 cases per 100,000 inhabitants. No autochthonous cases have been reported since 2005 and the country was certified malaria-free by the WHO in 2011 [8].

Mosquito-borne arboviruses circulate in Armenia, without significantly threatening public and animal health. A large entomological survey conducted from 2003 to 2006 by the Armenian Institute of Epidemiology, Virology, and Medical Parasitology, identified 125 distinct strains of arboviruses isolated from 64,567 field-caught mosquitoes, including West Nile virus and others viruses like the Batai, Sindbis, Tahyna and Gheta viruses, without registered human or animal cases [19, 20].

In response to the $P$. vivax malaria outbreak, a national network of entomologists was established during the 1990s, and continues to operate today. Medical entomologists are active in all regions and Yerevan territorial branches of the National Center of Disease Control and Prevention (NCDC), with leadership at the National level - Reference Laboratory Center of NCDC at the Ministry of Health. Most entomological surveillance in Armenia focuses on anopheline mosquitoes, with registration of all stagnant water bodies throughout Armenia by routine investigation of stagnant water bodies for larvae and barns for adults every 10 days. Sampling techniques include dipping for larvae and adult resting catches with tubes from the walls of barns. Routine vector control activities rely mainly on the use of mosquito-larvivorous fish Gambusia affinis, and more rarely on insecticide spraying and the reduction of mosquito larval breeding sites [7].

The anopheline species, locally named "malaria mosquitoes", are the most studied mosquitoes in Armenia. The Anopheles maculipennis complex is represented locally by two species. The first, An. sacharovi Favre, was the main malaria vector, with a marked anthropophilic biting behaviour. It is present in regions where rice is cultivated, in the central part of the Ararat Valley. The second, An. maculipennis s.s.
Meigen, is widely distributed in the whole country. It is more zoophilic than An. sacharovi and therefore considered only a secondary malaria vector. In the late 1950 s and the early 1960s, the An. maculipennis complex was thought to be eliminated from most of Armenia, but the use of insecticide was discontinued in the late 1960s and the numbers of An. maculipennis s.s. were restored, whereas An. sacharovi was not detected before the late 1990s. Several surveys of this complex were performed in the 1990s and 2000s using molecular methods for species differentiation [17, 23, 31].

VectorNet is a joint project of the European Centre for Disease Prevention and Control (ECDC) and the European Food Safety Authority (EFSA) supporting the collection of distribution data on vectors of pathogens, related to both human and animal health. An international VectorNet field mission reported the presence of Aedes aegypti (Linnaeus) in Georgia at $20 \mathrm{~km}$ north of the Georgia-Armenia border in September 2015 [1]. Here, we report results of another VectorNet field mission conducted in 2016 in Armenia with the aim of improving knowledge of the under-studied mosquito fauna (i.e. culicines) and assessing the presence and distribution of invasive mosquitoes, with special focus on the main arbovirus vectors present in the south Caucasus and Middle East, Ae. aegypti, Ae. albopictus (Skuse), Culex perexiguus Theobald and Cx. tritaeniorhynchus Giles [12]. This field study was conducted as a snapshot survey (inspection of a maximum of sites within a short period of time in June-July 2016). To confirm and complete the observations, the survey was prolonged in August-October 2016. Finally, we report results of longitudinal surveys targeting West Nile vector species performed in 2017 and 2018 as part of the ECDC project "Development of a Tool to Appraise and Compare Vector Control Strategies against West Nile Fever in Europe" with the specific aim of evaluating mosquito population dynamics and relative abundance.

\section{Materials and methods}

In 2016, a snapshot field sampling campaign was performed from June 20 to July 12, 2016, in all 11 administrative units of Armenia, namely the 10 regions (Aragatsotn, Ararat, Armavir, Gegharkunik, Kotayk, Lori, Shirak, Syunik, Tavush, Vayotz Dzor) and the capital city of Yerevan (Fig. 1). A longitudinal survey focusing on a selected number of sites was performed in August-October 2016 as well as in MarchNovember 2017 and April-October 2018, in almost all Armenian regions (except Shirak and Gegharkunik) and in Yerevan.

Classical entomological methods were used, based on protocols defined for VectorNet field studies [11]. We mainly collected immature aquatic stages by dipping/netting. Occasionally, adults were collected with baited traps: All-Weather LED EVS traps (BioQuip, USA) baited with $\mathrm{CO}_{2}$ as dry ice, CDC Light Traps (CDCLT: Model 512, John W. Hock Company, USA), and BG Sentinel II ${ }^{\mathrm{TM}}$ traps (BGS: Biogents, Germany) baited with BG-Lure ${ }^{\mathrm{TM}}$ (Biogents, Germany) and $\mathrm{CO}_{2}$ as dry ice. Also, simple ovitraps were used to collect eggs from container breeding Aedes species [11]. In addition, resting adult mosquitoes were caught in animal shelters using aspirators 


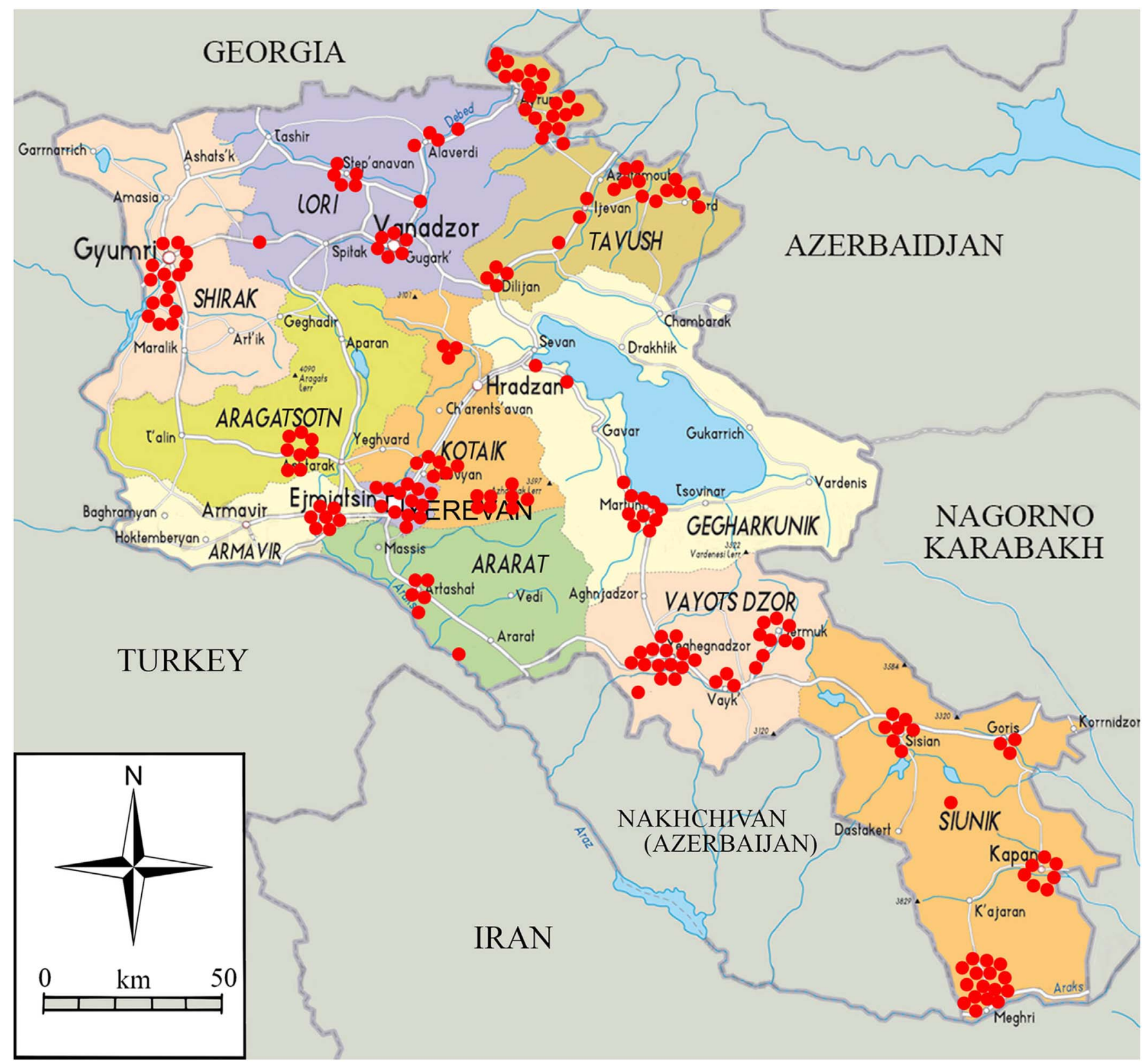

Figure 1. Location of the sampling sites in Armenia, June 20 to July 10, 2016.

and tubes. CDCLT, EVS and BGS traps were operated during the night, from at least $2 \mathrm{~h}$ before sunset up to $2 \mathrm{~h}$ after sunrise. They were placed in safe areas, avoiding the traps being damaged by animals or stolen. EVS and CDCLT were hung with the trap entrance at $1.5 \mathrm{~m}$ high and BGS placed on the ground. Finally, human landing catches was performed at daytime in Bagratashen (targeting Ae. albopictus). The collections were performed at varying frequency detailed in Tables S1-S4. Field data were reported using the VECMAP ${ }^{\circledR}$ system (Avia-GIS, Belgium), in particular its mobile telephone application.

Entomological observations were analysed per sampling unit, defined as a collection of mosquitoes using the same collecting method at the same site. For instance, larval sampling was performed at several points of a large marsh within the same sampling unit. A sampling unit could be positive or negative for mosquitoes. Thus, sampling units can be multiple at one site, using for instance both resting adult collection and ovitrapping. Some localities also had several sites (village, city, etc.).

The larvae and adult specimens were identified based on standard morphological keys [5, 15, 26]. Molecular identification by DNA isolation and amplification of part of the mitochondrial cytochrome oxidase subunit I gene (mt COI) was performed for a single specimen, as described elsewhere [27]. Pupae were reared to obtain adults. 
Table 1. Mosquito species/taxa reported to occur in Armenia in the literature, prior to 2016 ( $1=$ presence record).

\begin{tabular}{|c|c|c|c|c|c|c|c|}
\hline & $\begin{array}{c}\text { Terteryan and } \\
\text { Mirumyan [30] }\end{array}$ & $\begin{array}{l}\text { Romi } \\
\text { et al. [23] }\end{array}$ & $\begin{array}{l}\text { Manukyan } \\
\text { et al. [19] }\end{array}$ & $\begin{array}{l}\text { Manukyan } \\
\text { et al. [20] }\end{array}$ & $\begin{array}{c}\text { WHO } \\
\text { Europe [31] }\end{array}$ & $\begin{array}{l}\text { Keshishyan } \\
\text { et al. [17] }\end{array}$ & $\begin{array}{l}\text { Manukyan } \\
\text { et al. [18] }\end{array}$ \\
\hline Aedes (Och.) caspius & & 1 & 1 & 1 & & & 1 \\
\hline Aedes (Och.) dorsalis & & & & & & & 1 \\
\hline Aedes (Dah.) geniculatus & 1 & & & & & & 1 \\
\hline Aedes $($ Adm. $)$ vexans & 1 & & & & & & 1 \\
\hline Anopheles (Ano.) claviger & 1 & 1 & 1 & 1 & & & \\
\hline Anopheles (Ano.) hyrcanus & & & 1 & 1 & & & \\
\hline Anopheles (Ano.) maculipennis s.l. & 1 & 1 & 1 & 1 & 1 & 1 & \\
\hline Anopheles (Ano.) maculipennis s.s. & & 1 & & & 1 & 1 & \\
\hline Anopheles (Ano.) sacharovi & & 1 & & & 1 & 1 & \\
\hline Anopheles (Cel.) superpictus & 1 & & 1 & 1 & & & \\
\hline Culex (Mai.) hortensis & & & & 1 & & & 1 \\
\hline Culex (Cux.) mimeticus & & & & & & & 1 \\
\hline Culex (Bar.) modestus & & & & & & & 1 \\
\hline Culex (Cux.) pipiens & 1 & 1 & 1 & 1 & & & 1 \\
\hline Culex (Ncx.) territans & & & & & & & $1 *$ \\
\hline Culex (Cux.) theileri & & 1 & 1 & 1 & & & 1 \\
\hline Culiseta (Cus.) annulata & 1 & & & & & & 1 \\
\hline Culiseta (All.) longiareolata & 1 & & & & & & 1 \\
\hline Uranotaenia $(P f c$.$) unguiculata$ & & & & & & & 1 \\
\hline Total & 8 & 7 & 7 & 8 & 3 & 3 & 13 \\
\hline
\end{tabular}

* Cited as Culex (Ncx.) apicalis Adams, 1903.

\section{Results}

Our survey in 2016-2018 increased the number of mosquito species recorded in Armenia from 18 to 28. The presence of the invasive species Ae. albopictus was recorded at a single locality at a border point with Georgia, on the main road Tbilisi-Yerevan. Anopheles sacharovi, the main malaria vector in Armenia, was only found in the Ararat Valley.

\section{Historical records}

Table 1 summarises published mosquito records (reference sources are given in the table). Up to 2013, 18 species were known to occur in Armenia. Five mosquito species of the Anophelinae subfamily were listed: An. maculipennis s.l./s.s., An. sacharovi, An. hyrcanus (Pallas), An. superpictus Grassi and An. claviger (Meigen). As for the Culicinae subfamily, four genera were listed, namely Aedes, Culex, Culiseta and Uranotaenia. Four Aedes species were recorded: Ae. caspius Pallas which was found in many lowlands, Ae. vexans (Meigen) reported to be more widely distributed in various landscapes, Ae. dorsalis (Meigen) and Ae. geniculatus (Olivier) of which larvae were found in small natural reservoirs in the forest and forest-steppe zones where they were reported as aggressive biters. With six species, the genus Culex was highly represented, with $C x$. pipiens Linnaeus and $C x$. theileri Theobald as the most widely distributed species, $C x$. hortensis Ficalbi and $C x$. modestus Ficalbi only noted in the Ararat Valley, and $C x$. mimeticus Noè and $C x$. territans Walker only recorded in one study [18]. Two species of the genus Culiseta were listed, i.e. Cs. longiareolata (Macquart) found in the Ararat Valley only, and Cs. annulata (Schrank) more widely distributed. Finally, from the genus Uranotaenia, the species
Ur. unguiculata Edward was reported from the Ararat Valley to occur in temporary pools and small ponds.

\section{Field mission June 20-July 10, 2016}

A total number of 117 sites were visited (in all Armenian regions) and 197 sampling units were assessed, showing 143 to be positive for larvae and/or adults and 54 remaining negative (Tables 2 and 3, and Table S1). The positive sampling units harboured 1-6 mosquito species, with $37 \%(n=53)$ showing monospecific mosquito fauna (Fig. 2). A total number of 4157 mosquito specimens were observed (3152 larvae and 1005 adults - caught or emerged from pupae), belonging to 24 species/taxa. Ten species are new records for Armenia: Ae. albopictus, Ae. annulipes (Meigen), Ae. cataphylla Dyar, Ae. cinereus/geminus Meigen/Peus, Ae. flavescens (Müller), An. plumbeus Stephens, Coquillettidia richiardii (Ficalbi), CX. martinii Medschid, Cx. torrentium Martini and Cs. subochrea (Edwards).

Two adult Ae. albopictus females were collected for the first time in Armenia on July 7, 2016, by netting around humans, $100 \mathrm{~m}$ from a bridge over the Debeb River (in Bagratashen, Lori Province, Fig. 3), which is the border point on the main Tbilisi-Yerevan road.

A unique and poorly preserved specimen of Aedes sp. (collected in Gegharkunik on June 24, 2016) morphologically identified as "cataphylla/leucomelas/punctor", revealed a COI sequence (GenBank sequence submission number MT457072, Specimen 16-116ARM) showing 100 to $98.7 \%$ similarities with Ae. leucomelas (Meigen), 99.5-97.7\% similarities with Ae. cataphylla, and $90.6 \%$ similarity with Ae. punctor (Kirby). Because Ae. cataphylla was recorded in Gegharkunik province (Table 2 and Table S1) and Ae. leucomelas was never 
Table 2. Number of positive sites per mosquito species recorded in Armenia in 2016, according to regions. Asterisk indicates a first record for Armenia.

\begin{tabular}{|c|c|c|c|c|c|c|c|c|c|c|c|c|c|}
\hline & Aragatsotn & Ararat & Armavir & Gegharkunik & Kotayk & Lori & Shirak & Syunik & Tavush & Vayots Dzor & Yerevan & $\begin{array}{l}\text { Total no. } \\
\text { of sites }\end{array}$ & $\begin{array}{l}\text { Total no. of } \\
\text { specimens }\end{array}$ \\
\hline Aedes (Stg.) albopictus* & & & & & & & & & 1 & & & 1 & 2 \\
\hline Aedes (Och.) annulipes* & & & & 3 & & 1 & & & & 3 & & 7 & 15 \\
\hline Aedes (Och.) caspius & 3 & 4 & 3 & & & & 5 & 2 & 1 & & & 19 & 211 \\
\hline Aedes (Och.) cataphylla* & & & & 2 & & & & & & & & 2 & 2 \\
\hline $\begin{array}{l}\text { Aedes }(\text { Aed }) \text { cinereus/ } \\
\text { geminus* }\end{array}$ & & & & 1 & & & & & & & & 1 & 7 \\
\hline Aedes (Och.) flavescens* & & 1 & & 1 & & & 1 & & & & & 3 & 5 \\
\hline Aedes (Dah.) geniculatus & & & & & 2 & & & & 1 & 1 & & 4 & 18 \\
\hline Aedes (Adm.) vexans & 2 & 1 & 2 & & & 1 & & 1 & 7 & 8 & & 22 & 103 \\
\hline Anopheles (Ano.) claviger & & & & 2 & & & 2 & 3 & 4 & 3 & 2 & 16 & 85 \\
\hline $\begin{array}{l}\text { Anopheles (Ano.) } \\
\quad \text { maculipennis s.l. }\end{array}$ & 7 & 2 & 4 & & 3 & 1 & 5 & 7 & 14 & 6 & 2 & 51 & 625 \\
\hline $\begin{array}{l}\text { Anopheles (Ano.) } \\
\text { maculipennis s.s. }\end{array}$ & 4 & 1 & 2 & & & & & 1 & & 1 & & 9 & 31 \\
\hline $\begin{array}{l}\text { Anopheles (Ano.) } \\
\text { plumbeus* }\end{array}$ & & & & & & & & 1 & & & & 1 & 10 \\
\hline $\begin{array}{l}\text { Anopheles (Ano.) } \\
\text { sacharovi }\end{array}$ & & & 1 & & & & & & & & & 1 & 1 \\
\hline $\begin{array}{l}\text { Coquillettidia (Coq.) } \\
\text { richiardii* }\end{array}$ & & 2 & & & 1 & & & & & & & 3 & 7 \\
\hline Culiseta (Cus.) annulata & 2 & & 5 & & & & 4 & 4 & 1 & & 2 & 18 & 145 \\
\hline $\begin{array}{l}\text { Culiseta }(\text { All }) \\
\text { longiareolata }\end{array}$ & 1 & & & & 1 & 1 & & 8 & & 3 & 2 & 16 & 396 \\
\hline $\begin{array}{l}\text { Culiseta }(\text { Cus. }) \\
\text { subochrea* }\end{array}$ & 1 & & 1 & 3 & 1 & & 1 & 2 & 1 & & & 10 & 24 \\
\hline Culex (Mai.) hortensis & 1 & & & 3 & 1 & 3 & 2 & 8 & 4 & 1 & & 23 & 108 \\
\hline Culex $(N c x$. ) martinii $*$ & 1 & & & & & & & & & & & 1 & 1 \\
\hline Culex (Cux.) pipiens & 5 & 1 & 6 & 4 & 4 & 8 & 5 & 15 & 15 & 3 & 5 & 71 & 1562 \\
\hline Culex (Ncx.) territans & 1 & & & & 1 & & & 1 & 1 & 1 & & 5 & 41 \\
\hline Culex (Cux.) theileri & 4 & 3 & 3 & 6 & 2 & & 8 & 10 & 8 & 6 & 2 & 52 & 746 \\
\hline Culex (Cux.) torrentium* & & & & 1 & & & & 1 & & & & 2 & 4 \\
\hline $\begin{array}{l}\text { Uranotaenia }(P f c .) \\
\text { unguiculata }\end{array}$ & & & & & & & & & 2 & 1 & & 3 & 8 \\
\hline Total & 32 & 15 & 22 & 31 & 17 & 14 & 33 & 64 & 60 & 37 & 16 & 341 & 4157 \\
\hline $\begin{array}{l}\text { Total no. of sites per } \\
\text { region }\end{array}$ & 10 & 6 & 6 & 12 & 17 & 17 & 15 & 34 & 40 & 27 & 13 & 197 & \\
\hline
\end{tabular}


Table 3. Sampling effort of the surveys, according to period and sampling method.

\begin{tabular}{|c|c|c|c|c|c|c|}
\hline & Larval sampling & Adult trapping & Human bait & Resting catch & Ovitrap & Total \\
\hline Jun-Jul 2016 & 94 & 40 & 9 & 41 & 13 & 197 \\
\hline Aug-Oct 2016 & 19 & 9 & 1 & 0 & 0 & 29 \\
\hline Mar-Nov 2017 & 998 & 584 & 0 & 251 & 0 & 1833 \\
\hline Apr-Oct 2018 & 1302 & 26 & 2 & 753 & 0 & 2083 \\
\hline Total & 2413 & 659 & 12 & 1045 & 13 & 4142 \\
\hline
\end{tabular}

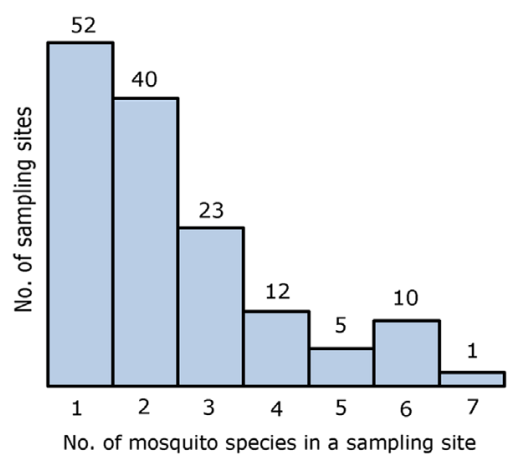

Figure 2. Number of sampling units that were found to be positive for mosquitoes (total $=143$ ), according to the number of mosquito species observed in each sampling, June 20 to July 10, 2016. Anopheles maculipennis s.l. is considered a "species" when no precise species from the complex is listed.

recorded in Armenia, we assign this specimen to Ae. cataphylla until additional and better preserved specimens can be clearly assigned to Ae. leucomelas.

Among the Anophelinae, An. maculipennis s.s. and An. claviger were the most prevalent species and were distributed in most of the regions. Anopheles sacharovi was observed in the Ararat Valley, and An. plumbeus was observed as larval stages in tyres in Syunik Province.

Among the Culicinae, the most common and numerous Aedes species was Ae. caspius, found in many regions except the highlands of the Sevan basin and Syunik; Ae. vexans was observed in all climatic zones and in various landscape conditions, at all places with temporary and subpermanent reservoirs. Larvae of Ae. geniculatus were found in small reservoirs temporarily filled with water, and in the forest and forest-steppe zones where adults are aggressive biters. Concerning the genus Culiseta, Cs. longiareolata was found in the Ararat, Aragatsotn, Kotayk and Gegharkunik regions, and in the city of Yerevan, and Cs. annulata was distributed in all types of landscapes in Armenia. Within the genus Culex, the most widely distributed species were $C x$. hortensis, $C x$. theileri and $C x$. pipiens; these three species were found in the lowland and foothill parts of the semi-desert area, as well as in forest and forest-steppe areas. Culex martinii, $C x$. territans and $C x$. torrentium presented lower abundances. Uranotaenia unguiculata was found in the Armavir, Kotayk, Ararat and Vayots-Dzor regions, in temporary pools or small ponds.

\section{Field mission August 3-October 30, 2016}

A total number of 19 sites were visited (in all regions except Aragatsotn, Ararat, Armavir and Syunik), and 29 sampling units were evaluated with 24 proving to be positive for mosquitoes and 5 negative (Table S2). The positive sampling units harboured 1-4 mosquito species and a total number of 166 mosquitoes (119 larvae and 47 adults) from 9 species/taxa. Aedes albopictus was again observed at the border point on the main road Tbilisi-Yerevan close to Bagratashen village (Fig. 3), with 14 and 6 adults caught by human landing catch on August 14 and September 28, respectively (30 min to $1 \mathrm{~h}$ catch during the day time).

\section{Field mission March 6-December 12, 2017}

A total number of 107 sites were visited (in all regions except Gegharkunik and Shirak), and 1393 sampling units were evaluated with 1379 proving to be positive for mosquitoes and 14 negative (Table S3). The positive sampling units harboured 1-8 mosquito species. A total number of 19,911 mosquitoes (16,305 larvae and 3606 adults) from 18 species were collected. Aedes albopictus was observed at the same location as in 2016 as biting adults (6, 5, and 7 females on June 12, August 15, and September 20, respectively, during the day time) (Fig. 3).

\section{Field mission April 3-October 31, 2018}

In 2018, the same sites were visited as in 2017, and 2085 sampling units were evaluated with 1212 found to be positive and 873 negative (Table S4). Positive sampling units included 1 to 5 mosquito species. A total number of 12,116 mosquitoes (7290 larvae and 4826 adults) were collected. Aedes albopictus was confirmed established at Bagratashen village by adult catches (29 females from August 22 to 24 during the day time) and for the first time also in Ayrum village (Tavush Province, Fig. 3), $10 \mathrm{~km}$ away from Bagratashen along the road to Yerevan, as larval and adult stages (3 larvae and 2 adults observed on August 23).

\section{Discussion}

Our results are important in terms of biodiversity but also in terms of public health. The most abundant mosquito species in our study in Armenia were found to be Ae. caspius, Cx. pipiens and An. maculipennis, consistent with previous studies [18-21, 23]. Ten mosquito species are new records for Armenia. This is a notable increase with regard to the total number of 28 species now reported (see full list in Appendix). The number of anopheline species has changed little from 5 to 6 , with the addition of An. plumbeus; this contrasts with the 9 species of Culicinae and confirms that the Culicinae had been neglected in Armenia prior to our studies. Our results also demonstrate the value of a snapshot field study, when performed at a suitable period and over a wide range of environments. 


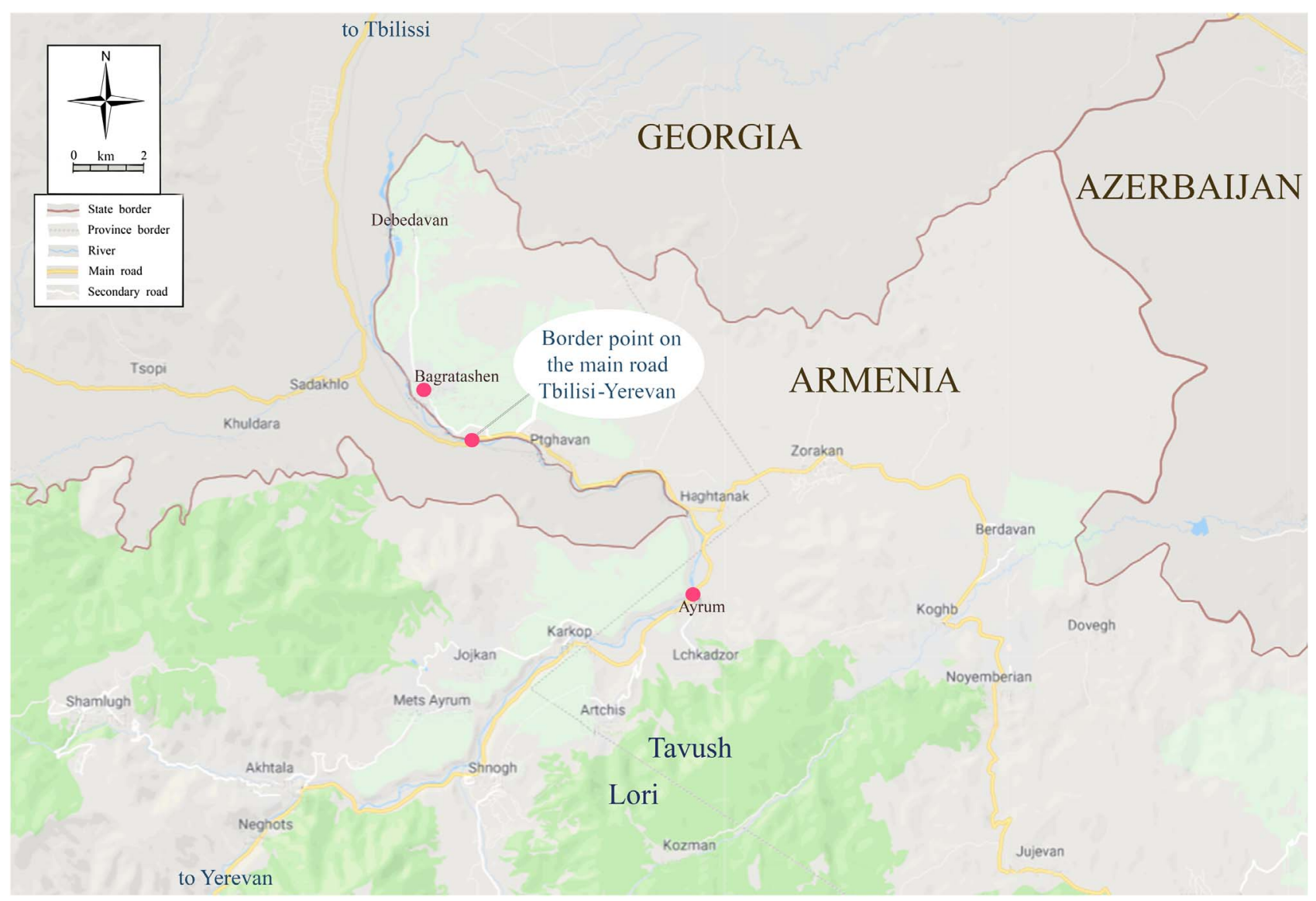

Figure 3. Location of the sites where Aedes albopictus was recorded in 2016-2018, north Armenia.

Interestingly, the field mission in 2016 was organised with the knowledge of the presence of Ae. aegypti at the border point with Georgia, where it had been recorded in 2015, $20 \mathrm{~km}$ away in a direct line towards the north [1]. Interestingly, no Ae. aegypti were observed, but instead Ae. albopictus. This unexpected observation means that we should expand some results geographically only with extreme caution.

The observation of one female only for Aedes cinereus/geminus is unfortunate because only males allow for a reliable differentiation between these two sibling species. Considering the distribution of the two species, the most probable to occur in Armenia is Ae. cinereus, since this species is present in Turkey and Georgia, in contrast to Ae. geminus ([22] and Table S5).

Although our sampling effort was limited, the absence of records for some mosquito species is surprising. However, future inventories will probably add new species. Table S5 lists mosquito species recorded in all surrounding countries (Georgia, Azerbaijan, north-western Iran, and eastern Turkey/Anatolia), which leads us to pay special attention to certain vector species: Ae. aegypti (recorded in Georgia and Turkey/Anatolia), $C x$. perexiguus (recorded in north-western Iran) and Cx. tritaeniorhynchus (recorded in Georgia, Azerbaijan and Turkey/Anatolia).

Aedes dorsalis was previously observed in Armenia [18], but not in our 2016-2018 surveys, which is puzzling. It is highly possible that, in the previous studies, Ae. dorsalis had been misidentified and confused with white morphotypes of
Ae. caspius, as proposed by Günay et al. [14] for specimens from the Ararat Valley in Turkey [3].

Aedes albopictus is an important potential vector of many arboviruses. A recent introduction into Armenia with Georgian geographic origin is most probable but not demonstrated. We collected evidence of the establishment of this invasive species with consecutive records made at the border point along the Tbilisi-Yerevan road in 2016 (from August 11 to September 28), in 2017 (June 13), and in 2018 (August 23). The potential of dispersion within Armenia along this main road axis must not be underestimated. In fact, we recorded the species in 2018 in Ayrum village, $10 \mathrm{~km}$ away from the border point. Close follow-up of the current dispersion in Armenia will be much needed during the coming years. This requires an adjustment of entomological surveillance activities in Armenia. Medical entomologists are active only in the NCDC. Routine entomological surveillance is carried out all over the country with the following objectives: entomological monitoring, implementation of vector control activities with special measures at points of entry, prevention of endemic vector-borne infectious diseases, scientific and applied research on vectors, and communication to raise awareness of vector control measures among the population. Up to 2016, entomological surveillance in Armenia focused on anophelines only ("malaria mosquitoes" versus "non-malaria mosquitoes"). Methodological tools for entomological surveillance were updated, and new sampling protocols and reporting forms were adopted; this allows us 
now to also efficiently survey culicine mosquitoes. All these improvements show the added value for public health in terms of knowledge improvement and capacity building for an up-todate mosquito surveillance system. This will help to prevent and mitigate mosquito-borne diseases in Armenia.

\section{Conclusion}

Knowledge of the mosquito fauna of Armenia is progressing. It now encompasses 28 species, with 10 species recorded for the first time in the present study. The presence of Ae. albopictus in the extreme north of Armenia, along an important access road (Tbilisi-Yerevan) is a major finding and holds implications for public health in terms of the risk of arbovirus transmission. Following this survey, entomological surveillance was reorganised in Armenia to include invasive mosquitoes in addition to the anopheline malaria vectors.

\section{Supplementary material}

Supplementary material is available at https://www.parasitejournal.org/10.1051/parasite/2020039/olm

Tables S1-S4: Detailed mosquito collection data in Armenia for June to July 2016, August to October 2016, March to November 2017, and April to October 2018, respectively.

Table S5: Mosquito species recorded in Armenia and in the surrounding countries.

Acknowledgements. Medical entomologists acting in all regional and Yerevan territorial branches of the NCDC participated in VectorNet training and the field mission, and learned new sampling techniques and identification tools. For the first time, mosquito traps provided by VectorNet were used in Armenia, as well as the VECMAP $^{\circledR}$ software and its mobile telephone application. LP, FS and VR are members of the VectorNet consortium. LP and VR belong to the entomology working group in the MediLabSecure network. We thank Dominique Bicout who coordinated the "Development of a Tool to Appraise and Compare Vector Control Strategies against West Nile Fever in Europe" project, funded by the European Centre for Disease Prevention and Control (ECDC) (Framework Service Contract No ECDC/2016/031) for accepting to share data from field monitoring with us. The MediLabSecure 1 project is supported by the European Commission (DEVCO: IFS/ 21010/23/_194); the MediLabSecure 2 project is funded by the European Union. The work under the VectorNet project of the ECDC and the European Food Safety Authority (EFSA) was implemented through a Framework Service Contract OC/EFSA/AHAW/ 2013/02-FWC1 with Avia-GIS.

\section{Conflict of interest}

The authors report that they have no competing interests.

\section{References}

1. Akiner MM, Demirci B, Babuadze G, Robert V, Schaffner F. 2016. Spread of the invasive mosquitoes Aedes aegypti and Aedes albopictus in the Black Sea region increases risk of chikungunya, dengue, and Zika outbreak in Europe. PLoS Neglected Tropical Diseases, 10(4), e0004664.
2. Aldemir A, Bedir H, Demirci B, Alten B. 2010. Biting activity of mosquito species (Diptera: Culicidae) in the Turkey-Armenia border area, Ararat Valley, Turkey. Journal of Medical Entomology, 47(1), 22-27.

3. Alten B, Bellini R, Caglar SS, Simsek FM, Kaynas S. 2000. Species composition and seasonal dynamics of mosquitoes in the Belek region of Turkey. Journal of Vector Ecology, 25, 145-164.

4. Avetisian LM. 2004. Epidemiological surveillance of parasitic diseases in the republic of Armenia. Meditsinskaia Parazitologiia (Moskow), 2004(1), 21-24 [in Russian].

5. Becker N, Petric D, Zgomba M, Boase C, Madon M, Dahl C, Kaiser A. 2010. Mosquitoes and their control, 2nd edn. Heidelberg: Springer. $577 \mathrm{p}$.

6. Chubkova AI, Pirumov KN, Sarkisyan MA, Manukyan LV, Hovsepyan LA. 1973. Malaria prophylactic in USSR. Konf. Lenkoran, Materials of the Lenkoran Conference, p. 33-38.

7. Davidiants V, Mannrikian M, Sayadian G, Parunakian A, Davtian B. 1998. Epidemic malaria transmission - Armenia, 1997. Morbidity and Mortality Weekly Report (CDC, USA), 47 (25), 526-528.

8. Davidyants VA, Kondrashin AV, Vanyan AV, Morozova LF, Turbabina NA, Stepanova EV, Maksimova MS, Morozov EN. 2019. Role of malaria partners in malaria elimination in Armenia. Malaria Journal, 18(1), 178.

9. Dehghan H, Sadraei J, Moosa-Kazemi SH, Abolghasemi E, Solimani H, Nodoshan HJ, Najafi MH. 2016. A pictorial key for Culex pipiens Complex (Diptera: Culicidae) in Iran. Journal of Arthropod-Borne Diseases, 10(3), 291-302.

10. Di Luca M, Boccolini D, Marinuccil M, Romi R. 2004. Intrapopulation polymorphism in Anopheles messeae (An. maculipennis complex) inferred by molecular analysis. Journal of Medical Entomology, 41(4), 582-586.

11. European Centre for Disease Prevention and Control, European Food Safety Authority. 2018. Field sampling methods for mosquitoes, sandflies, biting midges and ticks - VectorNet project 2014-2018. Stockholm and Parma: ECDC and EFSA. https://doi.org/10.2900/416333.

12. European Centre for Disease Prevention and Control (ECDC), European Food Safety Agency (EFSA), VectorNet. 2018. Mosquito maps. Available at http://ecdc.europa.eu/en/healthtopics/ vectors/vectormaps/Pages/VBORNET_maps.aspx, accession on 10 May 2020.

13. Grigorian G, Solkhomonian L. 2001. Armenia: implementation of national program of malaria control. Meditsinskaia Parazitologiia (Moskow), 2001(1), 21-24 [in Russian].

14. Günay F, Alten B, Simsek F, Aldemir A, Linton YM. 2015. Barcoding Turkish Culex mosquitoes to facilitate arbovirus vector incrimination studies reveals hidden diversity and new potential vectors. Acta Tropica, 143, 112-120.

15. Günay F, Picard M, Robert V. 2017. MosKeyTool, an interactive identification key for mosquitoes of Euro-Mediterranean. Version 2.1. Available at http://medilabsecure.com/moskeytool, accessed 10 May 2020.

16. Harbach RE. 2013. The phylogeny and classification of Anopheles, in Anopheles mosquitoes - New insights into malaria vectors. Manguin S, Editor. InTech: Rijeka, Croatia. p. 1-55.

17. Keshishyan A, Gordeev MI, Bezzhonova OV, Goriacheva II, Zvantsov AB, Davidiants VA, Ezhov MN. 2009. Genetic analysis of malaria mosquitoes of Anopheles maculipennis (Diptera, Culicidae) complex from Armenia. Meditsinskaia Parazitologiia (Moskow), 2009(3), 24-28 [in Russian].

18. Manukyan DV, Keshishyan A, Melik-Andreasyan GG, Hovsepyan AA. 2013. Fauna of non-malarian mosquitos of Armenia. Republic of Armenia, Ministry of Health, A.B. Alexsanyana Scientific: Yerevan. p. 145-148 [in Armenian]. 
19. Manukyan DV, Oganesian AS, Shakhnazarian SA, Aleksanian IuT. 2006. Role of mosquitoes in the transmission of arboviruses in Armenia. Meditsinskaia Parazitologiia (Moskow), 2006(2), 38-39 [in Russian].

20. Manukyan DV, Oganesian AS, Shakhnazarian SA, Aleksanian IuT. 2006. The species composition of mosquitoes and ticks in Armenia. Meditsinskaia Parazitologiia (Moskow), 2006(1), 31-33 [in Russian].

21. Ovsepian LA. 1982. Breeding sites of Culex pipiens L. mosquitoes in the viniculture regions of Armenia. Meditsinskaia Parazitologiia (Moskow), 51(4), 67-70 [in Russian].

22. Robert V, Günay F, Le Goff G, Boussès P, Sulesco T, Khalin A, Medlock J, Kampen H, Petrić D, Schaffner F. 2019. Distribution chart for Euro-Mediterranean mosquitoes (western Palaearctic region). Journal of the European Mosquito Control Association, 37, 1-28.

23. Romi R, Boccolini D, Hovanesyan I, Grigoryan G, Di Luca M, Sabatinelli G. 2002. Anopheles sacharovi (Diptera: Culicidae): a reemerging malaria vector in the Ararat Valley of Armenia. Journal of Medical Entomology, 39(3), 446-450.

24. Sabatinelli G. 1999. Determinants in malaria resurgence in the former USSR. Giornale Italiano di Medicina Tropicale, 4(3-4), $53-62$.

25. Sabatinelli G, Jorgensen P. 2001. Malaria in the WHO European Region (1971-1999). Eurosurveillance, 6(4), 61-65.
26. Schaffner F, Angel G, Geoffroy B, Hervy JP, Rhaiem A, Brunhes J. 2001. Les moustiques d'Europe, Logiciel d'identification et d'enseignement. CR-ROM. Collection Didactiques. Paris, France: IRD Editions.

27. Schönenberger AC, Wagner S, Tuten HC, Schaffner F, Torgerson P, Furrer S, Mathis A, Silaghi C. 2016. Host preferences of host-seeking and blood-fed mosquitoes in Switzerland. Medical and Veterinary Entomology, 30(1), 39-52.

28. Sergiev VP, Baranova AM, Majori G, Ejov MN. 2006. Malaria in the European Region of the World Health Organization, 1970-2000. Copenhagen, Denmark: WHO Regional Office for Europe.

29. Sedaghat MM, Linton YM, Nicolescu G, Smith L, Koliopoulos G, Zounos A, Oshaghi MA, Vatandoost H, Harbach RE. 2003. Morphological and molecular characterization of Anopheles (Anopheles) sacharovi Favre, a primary vector of malaria in the Middle East. Systematic Entomology, 28(2), 241-256.

30. Terteryan AE, Mirumyan LS. 1989. Pre imaginal stages of mosquitoes (Diptera, Culicidae) in the Lake Sevan basin (Armenia). Biologicheskiı̌ Zhurnal Armenii, 42, 467-470 [in Armenian].

31. WHO Europe. 2008. Mosquitoes of the genus Anopheles in countries of the WHO European Region having faced a recent resurgence of malaria. Regional research project, 2003-2007. Copenhagen, Denmark: WHO. 26 p.

\section{Appendix}

Annotated checklist of the 28 mosquito species of Armenia

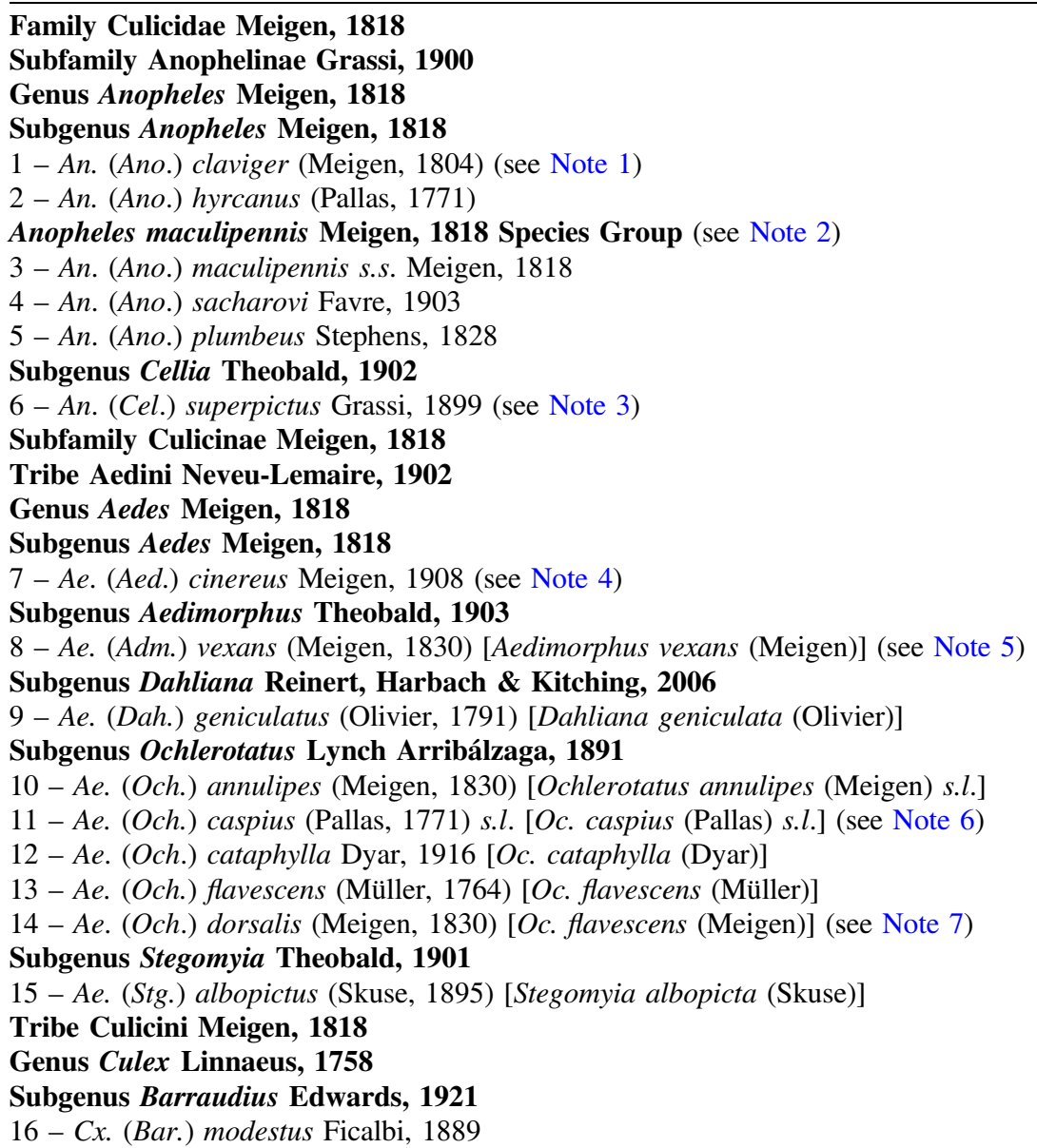


Continued

Subgenus Culex Linnaeus, 1758

$17-$ Cx. (Cux.) mimeticus Noè, 1899

$18-C x$. (Cux.) pipiens Linnaeus, 1758 (see Note 8)

$19-$ Cx. (Cux.) theileri Theobald, 1903

$20-C x$. (Cux.) torrentium Martini, 1925

Subgenus Maillotia Theobald, 1907

$21-C x$. (Mai.) hortensis Ficalbi, 1889

Subgenus Neoculex Dyar, 1905

$22-C x$. (Ncx.) martinii Medschid, 1930

$23-C x$. (Ncx.) territans Walker, 1856 (see Note 9)

Tribe Culisetini Belkin, 1962

Genus Culiseta Felt, 1904

Subgenus Allotheobaldia Broelemann, 1919

24 - Cs. (All.) longiareolata (Macquart, 1838)

Subgenus Culiseta Felt, 1904

25 - Cs. (Cus.) annulata (Schrank, 1776)

26 - Cs. (Cus.) subochrea (Edwards, 1921)

Tribe Mansoniini Belkin, 1962

Genus Coquillettidia Dyar, 1905

Subgenus Coquillettidia Dyar, 1905

27 - Cq. (Coq.) richiardii (Ficalbi, 1889)

Tribe Uranotaeniini Lahille, 1904

Genus Uranotaenia Lynch Arribálzaga, 1891

Subgenus Pseudoficalbia Theobald, 1912

28 - Ur. (Pfc.) unguiculata Edwards, 1913

Note 1 Member of the An. claviger complex. Anopheles petragnani is absent from the Caucasus.

Note 2 An. maculipennis complex. Two species only are present: An. maculipennis s.s. and An. sacharovi. Ribosomal RNA gene sequences are available for both species [10]. Anopheles maculipennis s.s. is the most abundant Anopheles species in Armenia, and An. sacharovi is an important malaria vector in the Middle East [29].

Note 3 An. superpictus. Old record [30] at larval stage. Identification likely reliable because this species belongs to the Cellia subgenus.

Complex of several species observed in Iran, listed as species A and B by Harbach [16].

Note 4 An. cinereus is more likely in Armenia because it has been found in the region, unlike Ae. geminus.

Note 5 Ae vexans subspecies. Presence of Ae. vexans vexans.

Note 6 Ae. caspius subspecies. Presence of Ae. caspius caspius. Abundant in lowland plains.

Note 7 Ae. dorsalis. Uncertain for presence; possible misidentification. Previous records in Armenia [18] at densities higher for Ae. dorsalis than for Ae. caspius, which is suspect. Recent records in the Ararat Valley (right bank, Turkey [2]) are now considered to be a "pale form" of Ae. caspius (Alten \& Günay, Personal communication). Not observed in our studies.

Note 8 Cx. pipiens complex. Evidence of presence of the anthropophilic $C x$. pipiens biotype molestus, the most abundant mosquito species in Armenia. Absence of $C x$. quinquefasciatus (present in southern half of Iran [9]).

Note 9 Cx. territans. Recorded as Cx. apicalis Adams, 1903 (a north American species) in [18].

Cite this article as: Paronyan L, Babayan L, Manucharyan A, Manukyan D, Vardanyan H, Melik-Andrasyan G, Schaffner F \& Robert V. 2020. The mosquitoes of Armenia: review of knowledge and results of a field survey with first report of Aedes albopictus. Parasite $27,42$.

O PARASTE

Reviews, articles and short notes may be submitted. Fields include, but are not limited to: general, medical and veterinary parasitology; morphology, including ultrastructure; parasite systematics, including entomology, acarology, helminthology and protistology, and molecular analyses; molecular biology and biochemistry; immunology of parasitic diseases; host-parasite relationships; ecology and life history of parasites; epidemiology; therapeutics; new diagnostic tools.

All papers in Parasite are published in English. Manuscripts should have a broad interest and must not have been published or submitted elsewhere. No limit is imposed on the length of manuscripts.

Parasite (open-access) continues Parasite (print and online editions, 1994-2012) and Annales de Parasitologie Humaine et Comparée (1923-1993) and is the official journal of the Société Française de Parasitologie.
Submit your manuscript at http://parasite.edmgr.com/ 